\title{
PROBLEMAS Y CONTRADICCIONES DE LA REGULACIÓN DE LA CLÁUSULA DE CONCIENCIA PERIODÍSTICA
}

DANIEL CAPODIFERRO CUBERO 
SUMARIO

1. INTRODUCCIÓN. 2. LA MODULACIÓN DE LA LIBERTAD DE EXPRESIÓN DE LOS PROFESIONALES DE LA INFORMACIÓN A PARTIR DE SU RELACIÓN CON UN MEDIO DE COMUNICACIÓN. 3. LOS PROBLEMAS DE LA FUNDAMENTACIÓN NORMATIVA DE LA CLÁUSULA DE CONCIENCIA Y LA DIVERSIDAD DE BIENES JURÍDICOS PROTEGIDOS. 4. LA DETERMINACIÓN DE LOS TITULARES DEL DERECHO. 5. CONTENIDO Y ALTERNATIVAS A LA CLÁUSULA DE CONCIENCIA DE BASE IDEOLÓGICA DEL ART. 2 DE LA LO 2/1997. 6. LA CLÁUSULA DE CONCIENCIA RESISTENTE. 7. CONCLUSIONES. 8. BIBLIOGRAFÍA. 


\title{
PROBLEMAS Y CONTRADICCIONES DE LA REGULACIÓN DE LA CLÁUSULA DE CONCIENCIA PERIODÍSTICA
}

\author{
DANIEL CAPODIFERRO CUBERO \\ Investigador Postdoctoral \\ Departamento de Ciencia Política y Derecho Público \\ U. Autónoma de Barcelona.
}

\section{INTRODUCCIÓN}

Las libertades consagradas en el art. 20 CE cumplen una función privilegiada dentro del vigente modelo jurídico-político. Además de derechos subjetivos fundamentales de todos los ciudadanos, se presentan como el instrumento que permite garantizar la formación y la existencia de la opinión pública libre, base sobre la que se construye el pluralismo político que, a su vez, representa el valor fundamental y el requisito básico de funcionamiento del Estado democrático ${ }^{1}$. Sin una comunicación libre los derechos fundamentales, especialmente los de carácter político y participativo, se vaciarían de contenido real, falseando el principio de legitimidad democrática del art. 1.2 $\mathrm{CE}^{2}$. Por ello, resulta lógico que el Ordenamiento articule garantías especiales para asegurar su correcta materialización en una doble vertiente. Por una parte, estableciendo límites y pautas para la actuación informativa que permitan garantizar su veracidad y

1 STC 12/1982, de 31 de marzo, FJ 3. ${ }^{\circ}$, reiterada en múltiples ocasiones, la más reciente la STC 23/2010, de 27 de abril, FJ 5. ${ }^{\circ}$

${ }^{2}$ STC 6/1981, de 16 de marzo, FJ 3. ${ }^{\circ}$ 
proteger a los ciudadanos frente a injerencias ilegítimas en su derecho al honor, la intimidad y la propia imagen. Y por otra, reconociendo prerrogativas especiales para los profesionales de la información cuyo trabajo consiste, precisamente, en construir y transmitir contenidos a través de los medios de comunicación, considerados un vehículo privilegiado para la formación de la opinión pública ${ }^{3}$.

Entre estas últimas se situaría la cláusula de conciencia, que el art. 20.1.d) $\mathrm{CE}$ recoge, junto con el secreto profesional, como un derecho fundamental de los profesionales de la información al tiempo que se remite a la Ley para que configure, sin ningún tipo de pauta o condicionante expreso, su contenido, alcance o límites. La simple mención constitucional de esta posibilidad ya la convierte en una facultad que no requiere para su aplicación mención expresa en norma o contrato alguno ${ }^{4}$; no obstante, dada la total omisión del precepto respecto del contenido o fundamento del derecho, se impone la necesidad de su desarrollo. Ante la pasividad del Legislador, fue mediante los Estatutos de Redacción de diversos medios, instrumentos de autorregulación del sector periodístico al margen de la intervención del Estado ${ }^{5}$, como se articuló el contenido de la institución hasta el dictado de la LO 2/1997, de 19 de junio. Sin embargo esta norma, lejos de contener el marco jurídico completo del derecho, se plantea en unos términos muy poco ambiciosos que no agotan el contenido posible de la previsión constitucional ${ }^{6}$, dejando en el aire tanto la determinación o la viabilidad como la forma de ejercer aquellas facultades no positivizadas que pudieran integrarse en su contenido esencial.

En cualquier caso, frente al enfoque mayoritario que concibe esta institución como una simple peculiaridad moduladora del cumplimiento y de la extinción de las obligaciones laborales en un determinado sector productivo, la idoneidad de la Ley debe evaluarse a la luz de la función y los objetivos que la jurisprudencia del Tribunal Constitucional ha atribuido a la cláusula de conciencia en el

3 STC 165/1987, de 27 de octubre, FJ 10.

${ }^{4}$ Carreras Serra, L. (1996). Régimen jurídico de la información: periodistas y medios de comunicación, Barcelona, Ariel, p. 170.

5 Sobre el alcance de la capacidad de autorregulación de los medios, Vid. Gavara DE CARA, J. C. (2013). «La autorregulación como mecanismo de autocontrol de los medios de comunicación: intervención pública y regulación interna», en Gavara de Cara, J. C.; De Miguel Bárcena, J. (Eds.). La autorregulación de los medios de comunicación como sistema de control, Barcelona, Bosch, pp. 41 y s.

${ }^{6}$ Carrillo, M. (1997). «La Ley Orgánica de la cláusula de conciencia de los periodistas: una garantía atenuada del derecho a la información». Cuadernos de Derecho Público, n. ${ }^{\circ} 2$, p. 188-189. Sobre las posibles facultades que, pese a no estar en la Ley, podrían ejercitarse por el profesional de la información mediante la invocación directa del art. 20.1.d) CE, Vid. Azurmendi, A. (2011). Derecho de la comunicación, Barcelona, Bosch, p. 203-204. 
sistema jurídico. Además, debe considerarse la necesaria fuerza expansiva que corresponde a un derecho fundamental, sobre todo si se entiende como una derivación de la libertad de pensamiento ${ }^{7}$.

\section{LA MODULACIÓN DE LA LIBERTAD DE EXPRESIÓN DE LOS PROFESIONALES DE LA INFORMACIÓN A PARTIR DE SU RELACIÓN CONTRACTUAL CON UN MEDIO DE COMUNICACIÓN}

Desde una perspectiva ideal, la correcta realización de la actividad informativa institucionalizada resulta del ejercicio de la, genérica, libertad de expresión de los profesionales del ámbito de la comunicación, entendida como el derecho que comprende la transmisión tanto de datos objetivos como de ideas, opiniones o puntos de vista subjetivos sobre los primeros ${ }^{8}$, componentes todos ellos del mensaje informativo de modo difícilmente separable ${ }^{9}$. Sin embargo, a la vista de la configuración del sector, el protagonismo en el proceso de generación y transmisión de información a la sociedad no se otorga a los sujetos individualmente considerados, sino a los medios de comunicación donde los profesionales deberán integrarse, casi sin remedio, para realizar su labor.

Esto supone que la libertad de expresión individual en la comunicación institucionalizada nunca podrá ser plena, sino que se verá sometida a modulaciones. En los medios públicos a causa de su necesaria neutralidad ideológica ${ }^{10}$, y, especialmente, en los de titularidad privada por el deber de respetar su carácter de organizaciones de tendencia ${ }^{11}$, dotadas de una línea de opinión propia. Así, el profesional de la información que desarrolle su labor en este segundo

7 Escobar Roca, G. (2002). Estatuto de los periodistas. Régimen normativo de la profesión y organización de las empresas de comunicación, Madrid, Tecnos, p. 192.

${ }^{8}$ Que son los términos en los que la consagra el art. 10 CEDH. Vid. Freixes Sanjuán, T. (2003). «El Tribunal Europeo de Derechos Humanos y las libertades de comunicación». Revista de Derecho Comunitario, n. ${ }^{\circ} 15$, p. 465.

9 STC 223/1992, de 14 de diciembre, FJ 1. ${ }^{\circ}$

${ }^{10}$ Aplicando la doctrina de la STC 5/1981, de 13 de febrero, FJ 9. , al afirmar que «En un sistema jurídico político basado en el pluralismo, la libertad ideológica y religiosa de los individuos y la aconfesionalidad del Estado, todas las instituciones públicas y muy especialmente los centros docentes, han de ser, en efecto, ideológicamente neutrales», en la medida en que los medios de comunicación públicos son instituciones de titularidad estatal, deben configurarse como empresas ideológicamente neutrales. En la misma línea, la STC 190/2001, de 1 de octubre, FJ 4. ${ }^{\circ}$, definió RTVE no como una empresa ideológica, sino como «un servicio público obligado a mantener neutralidad ideológica por el art. 103 CE».

${ }^{11}$ Llamazares Calzadilla, M. C. (1999). Las libertades de expresión e información como garantía del pluralismo democrático, Madrid, Civitas, pp. 141 y s. 
ámbito estará condicionado tanto en la faceta subjetiva de su trabajo (el enfoque de la noticia o la opinión) como en la objetiva (la propia descripción del hecho noticioso o la posibilidad de abordar o no determinados temas) por el sesgo marcado desde la dirección ${ }^{12}$, que buscará defender una determinada línea editorial. Pero esta limitación no puede ser entendida como absoluta. La existencia de un vínculo contractual con una empresa, aunque sea del ámbito de la comunicación y tenga como objeto la realización de una prestación ideológicamente cualificada, no puede suponer ni una renuncia a derechos ni la obligación de que exista una coherencia total o la plena sumisión del informador respecto de la ideología del medio. De las exigencias del principio de buena fe contractual sobre la libertad de expresión del informador no se deriva para éste un deber genérico de lealtad con un significado omnicomprensivo de sujeción al interés empresarial $^{13}$.

Por ello, el alcance de su libertad de expresión deberá ponderarse teniendo en cuenta el resto de bienes jurídicos relevantes presentes, dando como resultado una modalización temporal de la prestación a partir de los principios ideológicos o editoriales del medio que será admisible, en principio, mientras resulte necesaria para satisfacer el legítimo interés empresarial ${ }^{14}$. La garantía de éste permitirá someter la libertad de expresión de los profesionales de la información a aquellas limitaciones imprescindibles que, además, sean adecuadas y proporcionadas para su consecución aunque, al mismo tiempo, no se puede ignorar la existencia de otros bienes jurídicos superiores cuya satisfacción puede condicionar la relación entre empleado y empleador en este caso. Dada la especial importancia que la actividad de estas empresas tiene en la realización del principio democrático, los intereses privados de finalidad puramente mercantil que sugieran faltar al deber de veracidad o contradigan o no estén alineados claramente hacia el cumplimiento de los objetivos sociales de la libertades comunicativas no deberían considerarse dignos de prevalecer de ninguna manera sobre la actuación de un profesional que, siendo correcta desde el punto de vista de sus fines constitucionales, se aleje de la línea del medio; tal cosa sería una forma de convertir la información en una mera mercancía de intercambio en manos de las empresas ${ }^{15}$.

${ }^{12}$ Calvo Gallego, F. J. (1998). «Algunas reflexiones sobre la nueva Ley de la cláusula de conciencia». Relaciones Laborales, n. ${ }^{\circ} 1$, p. 396.

13 STC 20/2002, de 28 de enero, FJ 4. ${ }^{\circ}$

${ }^{14}$ Calvo Gallego, F. J. (1998). Supra, p. 398.

15 Cosa que para Abel Vilella, F. A. (2002). La concentración de los medios de comunicación social en los derechos español y comunitario, Madrid, Marcial Pons, p. 39-42, constituye un evidente peligro para la consecución del fin constitucional que se atribuye a la comunicación. 
La ponderación entre los intereses empresariales y los personales debe considerar la necesidad inexcusable de garantizar la conformación de una opinión pública libre y plural como finalidad del ejercicio activo e institucionalizado de la libertad de expresión en sentido amplio, para lo cual resulta imprescindible valorar antes la configuración normativa y la realidad del sector informativo. Si la oferta de éste muestra una variedad de opciones y enfoques subjetivos diferenciados a la sociedad, de modo que todo el espectro ideológico integrado en la ética pública se ve reflejado, esta premisa se podrá entender cumplida gracias a la pluralidad de $\operatorname{medios}^{16}$. Sin embargo, si no existe diversidad real, la única vía para garantizar el cumplimiento de la función social que se atribuye a la actividad comunicativa institucionalizada será asegurar el pluralismo interno en los medios. Considerando que éste es el resultado del ejercicio de la libertad de expresión individual de los profesionales dentro de la empresa, se puede concluir que la legitimidad de las limitaciones que se impongan sobre este derecho vendrá condicionada, en última instancia, por el grado de observancia del pluralismo externo en el conjunto.

A la vista de la coyuntura actual del sector de la comunicación español, no es descabellado afirmar que el pluralismo es un valor seriamente comprometido. Los medios se muestran progresivamente más politizados y polarizados en sus tendencias, sin dar cabida al pluralismo interno ${ }^{17}$, y otorgando cada vez más peso a cauces de expresión de la opinión cuyas formas son las de la propaganda doctrinaria, que en nada favorecen un verdadero debate en la sociedad. Junto a esto, la heterogeneidad ideológica que se muestra quizá sea más aparente que real, porque no todas las opciones admisibles en el Estado democrático tienen verdaderamente presencia ni reflejo en los medios; la exclusión de aquellas que no comparten determinados dogmas puede ayudar a estabilizar el sistema político, pero limita las posibilidades de elección y debate de la opinión pública. Además, hay que considerar el proceso de concentración empresarial que, con el beneplácito de los Poderes Públicos, experimentan los medios de comunicación privados, cuya titularidad se va acumulando en manos de grandes grupos editoriales con una línea ideológica propia que se proyectará, en mayor o menor medida, sobre todos aquellos que controlan, lo cual restringe la diversidad y limita el pluralismo efectivo en función de objetivos económicos que nada tienen que ver con la salvaguarda de los derechos de los ciudadanos ${ }^{18}$. Esto último supone, incluso, un

16 Vid. Llamazares Calzadilla, M. C. (1999). Cit. p. 146-148.

17 Abejón Mendoza, P. (2013). «Estado del periodismo de opinión en España: polarización, género y emolumentos». Zer. Revista de Estudios de Comunicación, vol. 18, n. ${ }^{\circ} 34$, p. 107-108.

18 Sobre esta cuestión, Vid. Abel Vilella, F. A. (2002). Cit. p. 131 y s. y 206 y s. 
problema para los profesionales de la información, cuyo mercado laboral se ve reducido, especialmente en caso de haber mostrado en alguna ocasión disconformidad o una actitud disidente con sus empleadores.

Ante este panorama, el cumplimiento de las finalidades constitucionalmente asignadas a las libertades del art. $20 \mathrm{CE}$ exige, como contrapartida, la presencia de medidas que aseguren el pluralismo en los medios, dotando a los profesionales de la información de instrumentos o prerrogativas que les permitan hacer valer su libertad de expresión de manera proporcionada y razonable y garanticen, en última instancia, su libertad de pensamiento. La cláusula de conciencia, como derecho fundamental, debería jugar un papel relevante en este sentido, aunque fuera como vía excepcional para garantizar esos derechos. Pero su utilidad dependerá del contenido concreto que se le atribuya por vía legislativa o jurisprudencial, y en el caso del Ordenamiento español la situación dista mucho de ser la idónea.

\section{LOS PROBLEMAS DE LA FUNDAMENTACIÓN NORMATIVA DE LA CLÁUSULA DE CONCIENCIA Y LA DIVERSIDAD DE BIENES JURÍDICOS PROTEGIDOS}

Ante la indefinición constitucional, el Legislador y el Tribunal Constitucional han optado por atribuir a la cláusula de conciencia una finalidad que, en última instancia, trasciende su sentido tradicional como garantía de la esfera subjetiva del periodista. Contextualizada por el art. 20.1.d) CE como un derecho vinculado a las libertades informativas, su desarrollo le reconoce un fundamento complejo y ambivalente, con una dimensión subjetiva y otra objetiva que responden, respectivamente, a una necesidad individual y a un interés del conjunto de la sociedad ${ }^{19}$, aunque, aparentemente, no con igual intensidad.

Normativamente, el art. 1 de la LO 2/1997 explicita que el objeto de la cláusula de conciencia es "garantizar la independencia de los profesionales de la información en el desempeño de su función». Se presenta como como la garantía de una determinada característica objetiva de la actividad del profesional de la información, la independencia profesional, que la norma parece asimilar a la integridad deontológica del periodista frente a hechos producidos en el seno de la empresa de comunicación que la cuestionen ${ }^{20}$. De hecho, parte de la doctrina ha entendido que la Ley ha desplazado el fundamento de la cláusula de conciencia del plano de

19 SuÁrez Espino, M. L. (2009). «Algunas reflexiones sobre el Estatuto Jurídico del Periodista en el Ordenamiento Jurídico español». Cuadernos de Derecho Público, n. ${ }^{\circ}$ 36, p. 43.

${ }^{20}$ Carrillo, M. (1997). Cit. p. 188. 
las ideas al de la ética profesional ${ }^{21}$, limitando su contenido a aquellas facultades que permitan al periodista ejercer su actividad «bajo el principio ineludible de la responsabilidad» (como señala la Exposición de Motivos) en las condiciones necesarias para garantizar la veracidad, objetividad y el pluralismo informativos ${ }^{22}$, eliminando cualquier concesión a la libertad ideológica. El profesional, por tanto, se beneficiaría del derecho únicamente por ser un «instrumento necesario y privilegiado para garantizar el derecho a la información de todos los ciudadanos frente a un uso ilegítimo de la capacidad de orientación y dirección informativa que ostenta el medio» ${ }^{23}$.

Pero esta lectura de la norma, en clave únicamente deontológica, olvida el importante componente subjetivo de la libertad de expresión e información como objeto de la prestación del profesional de la comunicación. Así concebida, la cláusula de conciencia se convierte en un mecanismo que refuerza la obligatoriedad de la ética profesional con una finalidad de alcance general, pero no se sostiene como un derecho subjetivo porque la protección de la esfera personal de su titular sería sólo una consecuencia indirecta, y de complicado alcance, de su invocación. Parece plantearse como un derecho al servicio de una aséptica libertad de prensa, entendida como una especialidad de los derechos de la comunicación que ampara la correcta y objetiva transmisión de información relacionada con asuntos de interés general especialmente trascendentes a efectos de debate público $^{24}$, cuando realmente es una garantía compleja e integral del ejercicio activo y efectivo de la profesión periodística, independiente del ámbito o el área temática sobre el que se proyecte. Y dado que la libertad de pensamiento es un elemento difícilmente separable de esta labor, no se puede extraer sin más del ámbito protegido por la cláusula de conciencia sin afectar a su esencia.

En esta línea, el Tribunal Constitucional se ha decantado por entender que la cláusula de conciencia es algo más que una garantía deontológica al afirmar

21 Aznar, H. (1998). «Cláusula de conciencia e información: de la ideología a la ética profesional». Revista de Estudios Políticos, n. ${ }^{\circ} 100$, pp. 300 y s.

22 Molina Navarrete, C. (1999). Empresas de comunicación y «cláusula de conciencia» de los periodistas, Granada, Comares, p. 72. En la misma línea, para Blasco Jover, C. (2009). El derecho a la cláusula de conciencia de los profesionales de la información, Albacete, Bomarzo, p. 97, el contenido de la cláusula de conciencia se limitaría a las facultades que permitieran al periodista hacer frente a conductas o comportamientos del empresario que pudieran poner en entredicho su libertad para informar y la veracidad de los hechos sobre los que se informa.

${ }^{23}$ Calvo Gallego, F. J. (1998). Cit. p. 422.

${ }^{24} \mathrm{Y}$ que para el TEDH es la que realmente resulta útil para el principio democrático, y no la libertad de expresión. Vid. VAldés Dal-RÉ, F. (2012). «Artículo 11. La libertad de expresión e información», en Monereo Atienza, C.; Monereo Pérez, J. L. (Dirs.). La Europa de los derechos. Estudio sistemático de la Carta de los Derechos Fundamentales de la Unión Europea, Granada, Comares, p. 235-236. 
que se trata de un derecho subjetivo que protege, de manera conjunta, «la libertad ideológica, el derecho de opinión y la ética profesional del periodista» ${ }^{25}$, puestos al servicio de la preservación del pluralismo (de la sociedad) como objetivo últi$\mathrm{mo}^{26}$. Ciertamente, el Alto Tribunal sólo realiza una enumeración casuística de los bienes protegidos por cada una de las modalidades reconocidas en la LO 2/1997 y los pone en relación con la finalidad esencial de las libertades comunicativas con objeto de dar cierta coherencia al conjunto. Pero al hacerlo, admite que la independencia profesional en el ámbito de la comunicación es merecedora de protección tanto en su faceta deontológica, que implica la posibilidad de desarrollar el trabajo de un modo acorde con las reglas de la ética de la profesión, como en la ideológica, equiparada a un espacio propio del sujeto en el ejercicio de su libertad de expresión e información frente a imposiciones de la empresa. La propia Exposición de Motivos de la Ley apunta en esta dirección al reconocer que los profesionales de la información ejercen «un trabajo presidido por un indudable componente intelectual» y no un proceso mecánico despojado de todo condicionante valorativo. Incluso se cita como un valor protegido directamente por este derecho la libertad de pensamiento, aunque lo lógico es entender que ésta operará como fundamento de la independencia moral del periodista para defenderse de imposiciones ideológicas ilegítimas del empresario que tengan algún tipo de repercusión en el desarrollo o resultado de su trabajo, pues en otros casos lo procedente sería invocar directamente el art. 16.1 CE, y no la cláusula de conciencia.

Es cierto que la protección de la independencia profesional se plantea como una garantía instrumental del correcto ejercicio del derecho a la información para que éste derive en la formación de una opinión pública libre (STC 225/2002, FJ $4^{\circ}$ ), atribuyendo a la cláusula de conciencia una finalidad con proyección pública e introduciendo como razón última de su presencia en el Ordenamiento el pluralismo social, que requiere que los ciudadanos puedan acceder de modo efectivo a una información no manipulada. Pero esto, lejos de reducir la importancia de la protección de la libertad de expresión de los encargados de generar los contenidos informativos, la aumenta. Además del respeto a la objetividad y

25 STC 225/2002, de 9 de diciembre, FJ 4. ${ }^{\circ}$

${ }^{26} \mathrm{Ibidem}, \mathrm{FJ} 2 .^{\circ}$ Anteriormente, la STC 199/1999, de 8 de noviembre, FJ 2. ${ }^{\circ}$, parece relacionar la cláusula de conciencia con los requisitos de objetividad y veracidad de la información, pero no con la libertad del profesional; de hecho la misma Sentencia, en el FJ 5. ${ }^{\circ}$, considera como criterio relevante para identificar una posible vulneración del derecho a la cláusula de conciencia el hecho de que la restricción impuesta al trabajador afecte a «la transmisión de información relevante para la formación de la opinión pública», pero no la incidencia que pudiera tener en sus convicciones personales de manera independiente ni sobre su autonomía. 
la veracidad, el pluralismo social también se nutre de la diversidad de interpretaciones legítimas y puntos de vista subjetivos sobre los hechos narrados; y en aquellas situaciones en las que esta amplitud de perspectivas necesite plasmarse a través del pluralismo interno en los medios (porque el externo se ve amenazado o reducido), la independencia ideológica de los profesionales individualmente considerados se convierte en un valor no sólo alineado con esa objetivo generalsocial de las libertades comunicativas, sino en la mejor manera de realizarlo. La garantía del derecho a recibir información es inseparable de la previa protección de la posición del informador, sin la cual es imposible asegurarla.

Por tanto, para cumplir la finalidad tan amplia y ambiciosa que se le ha atribuido (asegurar el adecuado ejercicio de la fundamental libertad de información ${ }^{27}$ ), la cláusula de conciencia debe configurarse de modo que garantice de manera efectiva, aunque sea una fórmula excepcional, tanto la posibilidad de actuar conforme a los parámetros de la ética profesional frente a imposiciones que exijan lo contrario, y que por definición serán ilegítimas, como la de proyectar la libertad de pensamiento individual en el ejercicio de la labor periodística, con mayor intensidad cuanto más necesario sea el pluralismo interno, aunque siempre al servicio de la veracidad y nunca entendida como un permiso para alterar de manera interesada el mensaje ${ }^{28}$. Cualquier limitación injustificada en estos ámbitos tendrá un efecto negativo sobre la formación de la opinión pública libre, ya que restringirá la posibilidad de los ciudadanos de obtener un determinado contenido informativo o una perspectiva concreta al respecto a la que, en condiciones normales, deberían poder acceder. Por tanto, debe entenderse que en el objeto y en el fundamento del reconocimiento de la cláusula de conciencia también se integra la libertad de expresión del profesional de la información como sujeto que realiza una labor intelectual de proyección pública con una clara aportación personal. Se trata de un trabajo de autor, y obviar la subjetividad que eso implica coloca a quienes lo llevan a cabo en riesgo de verse reducidos a la posición de simples generadores anónimos de contenidos noticiosos, en clara desventaja frente a la empresa y vulnerables ante cualquier imposición ajena al interés general.

Concebir la cláusula de conciencia como una prerrogativa sólo al servicio del derecho a recibir información de los ciudadanos supone vaciarla de contenido útil para el periodista aunque, en última instancia, se incorpore el factor ideológico a su esfera de protección. En estos términos, la posibilidad para el profesional de obtener la tutela que dispensa ante una lesión en su esfera personal por

27 STC 225/2002, de 9 de diciembre, FJ 2. ${ }^{\circ}$

28 Molina Navarrete, C. (1999). Cit. p. 117-118. 
parte de la empresa se verá condicionada por la afectación de un bien jurídico abstracto y general que, si bien es la consecuencia última de las labores que lleva a cabo, no constituye el objeto directo de su contrato laboral, que es el simple ejercicio institucionalizado de las libertades del ámbito de la comunicación. Parece pesar más el interés de la colectividad como destinataria de la información que las circunstancias propias del contrato o las desavenencias que puedan surgir durante su ejecución y afecten a la libertad de comunicación en sí misma y en toda su complejidad, lo cual resulta un tanto paradójico si se tiene en cuenta que el conjunto de facultades que comprende la cláusula de conciencia va a proyectar sus consecuencias únicamente en el desarrollo del propio vínculo laboral.

Además, supone colocar a los profesionales de la información en una posición similar a la de garante de los derechos del resto de ciudadanos; y de ser así, sería mucho más lógico caracterizar la cláusula de conciencia como un deber deontológico antes que como un derecho cuya materialización se deja en manos de la voluntad de su titular. Si se trata de una reacción motivada por la posible afectación del derecho general a recibir información veraz, y esta circunstancia se interpreta como algo particularmente grave que altera incluso la esencia del Estado democrático, su invocación debería ser obligatoria para todo profesional que, en el desempeño de su actividad, se viera ante alguna de las circunstancias objetivas que la motivan.

En el fondo, el desplazamiento a un segundo plano de la figura y los intereses subjetivos del profesional de la información que se desprende de la regulación y de los pronunciamientos del Tribunal Constitucional sobre la cláusula de conciencia sólo puede obedecer al interés de que ésta no sea interpretada de ningún modo como un supuesto de objeción de conciencia positivizado ${ }^{29}$. De concebirse así, el Ordenamiento estaría dotando a estos sujetos de una amplia posibilidad de modular y orientar el ejercicio de su actividad frente a las instrucciones, órdenes o directrices de la dirección de la empresa para la que trabajan. Es decir, de una independencia casi total, lo cual no termina de casar con la actual concepción del mercado de la comunicación y el alcance que tiene en el mismo la libertad de empresa. Por eso se justifica esencialmente como una garantía para los destinatarios de la información, situados en una posición de especial vulnerabilidad frente a un uso inadecuado de la libertad de prensa; pero por otro lado, estos, los ciudadanos, están liberados de los condicionantes que sí tendrán que soportar los profesionales del sector, y frente a los que la cláusula de conciencia no termina de constituir una respuesta eficaz porque no dota al periodista de

${ }^{29}$ Que es como la concibe Escobar Roca, G. (2002). Cit. pp. 192 y s. 
capacidad para oponerse a todas las posibilidades en las que puede materializarse el abuso de derecho por parte del empresario.

Dado lo subjetivo de su apreciación y la limitación de sus efectos a la relación contractual del sujeto activo, sería más lógico y práctico partir de la idea de que toda restricción ilegítima de la independencia del profesional va a tener, por definición, un efecto negativo sobre las demás libertades del art. 20 CE y, por tanto, debería permitir invocar la cláusula de conciencia. Así se equilibraría su doble carácter como garantía y derecho, orientándola de manera directa a proteger la esfera personal del profesional de la información en el ejercicio de sus funciones y su libertad de actuación a partir de sus convicciones y de las reglas deontológicas. Esto permitiría, en última instancia, garantizar el pluralismo interno en los medios en aquellas circunstancias en las que se viera ilegítimamente restringido o fuera más necesario, con lo que se estaría asegurando el correcto desempeño de la actividad de las empresas de comunicación y, en definitiva, la adecuada recepción de la información por parte de la sociedad.

\section{LA DETERMINACIÓN DE LOS TITULARES DEL DERECHO}

Antes de la aprobación de la LO 2/1997, y pese a que la Jurisprudencia Constitucional ya había remarcado que no sólo los profesionales de la información son sujetos activos del derecho a comunicar información consagrado en el art. 20.1.d) $\mathrm{CE}^{30}$, la doctrina apostaba por restringir la titularidad de la cláusula de conciencia a quienes desarrollasen de manera estable, y a cambio de una retribución permanente y fija, la profesión periodística ${ }^{31}$, trasponiendo, de manera muy evidente, el criterio seguido por la Legislación francesa ${ }^{32}$. El art. 2 de la LO 2/1997, en su redacción definitiva ${ }^{33}$, se limita a otorgar la legitimación activa para invocar

30 SSTC 105/1983, de 23 de noviembre, FJ 11. ${ }^{\circ}$, y 168/1986, de 22 de diciembre, FJ 5.

31 Escobar de la SERna, L. (1997). «La cláusula de conciencia como derecho fundamental en la Constitución de 1978», en Escobar de la Serna, L. (Dir.). La cláusula de conciencia, Madrid, Universitas, p. 7.

32 Donde se atribuye la titularidad de la cláusula de conciencia únicamente a «los periodistas profesionales asalariados», entendiendo por tales a quienes ejercen esa profesión de manera principal y regular, por cuenta ajena de alguna publicación diaria o periódica, y además obtienen de ello la remuneración que constituye su principal fuente de ingresos. Vid. Blasco Jover, C. (2009). Cit. p. 39-40.

33 El texto original de la Proposición de Ley Orgánica reguladora de la cláusula de conciencia de los periodistas (BOCG, Congreso de los Diputados, Serie B, n. ${ }^{\circ} 22-1$, de 7 de mayo de 1996) seguía la línea clásica y definía a los periodistas, titulares del derecho a la cláusula de conciencia, como «los profesionales que, como trabajo principal y retribuido, se dedican a obtener y elaborar información para difundirla o comunicarla públicamente por cualquier medio de comunicación técnico». 
la cláusula de conciencia a los «profesionales de la información», sin mayores precisiones, tratándolo como un derecho de tipo personal que no puede ser invocado por los medios o las empresas de comunicación como tales ${ }^{34}$. Se refuerza así el carácter de garantía subjetiva individual que deriva de su reconocimiento constitucional $^{35}$, aunque condicionada por la existencia de una relación que vincule al titular con medio de comunicación privado o público ${ }^{36}$. Pero en el caso de estos últimos, al no existir por definición orientación ideológica de la actividad periodística, las facultades del titular de la cláusula de conciencia estarían teóricamente limitadas a aquellas que le permitieran hacer frente a imposiciones de la dirección contrarias a la deontología profesional.

Con el fin de garantizar una mayor expansión del derecho, debería emplearse una noción amplia de empresa de comunicación, entendiendo que abarca no sólo los medios de comunicación en sentido estricto, sino también aquellos otros entes que, sin ser tales, participan en el proceso de generación de información como pueden ser, por ejemplo, las agencias de comunicación. No es relevante que los destinatarios de los contenidos generados por la empresa sean directamente los ciudadanos u otra empresa o medio de comunicación que lo reproducirá posteriormente de modo total o parcial con mayor o menor fidelidad, porque toda persona jurídica que actúe en este ámbito está sujeta al cumplimiento de los principios éticos del sector y tiene la capacidad de orientar ideológicamente su actividad. En todas ellas la libertad de actuación de los profesionales individuales se verá modulada por el derecho de los responsables a adoptar y transmitir una determinada visión subjetiva, por lo que son susceptibles de que surja en su seno un conflicto a causa de divergencias valorativas o sobre los criterios que deben regir el desarrollo de la actividad.

En cualquier caso, el vínculo del profesional con la empresa de comunicación debe implicar algún tipo de dependencia organizativa del primero respecto de la segunda. Normalmente será de carácter laboral ${ }^{37}$, aunque la titularidad del derecho no debería condicionarse a la existencia de un contrato de trabajo en sentido estric-

34 Carrillo, M. (1997). Cit. p. 187.

35 Fernández-Miranda Campoamor, A. (1996). «Artículo 20: libertad de expresión y derecho de la información», en Alzaga Villaamil, O. (Dir.). Comentarios a la Constitución Española, T. II, Madrid, Edersa, p. 542.

36 Porque, como apunta Escobar de la SERnA, L. (2003). «El TC y la cláusula de conciencia». Doxa comunicación, n. ${ }^{\circ} 1$, p. 135, para la jurisprudencia constitucional la titularidad de la cláusula de conciencia y el contenido y fines que se atribuyen son dos cuestiones unidas; el problema es que la propia regulación reduce esto a una declaración más teórica que práctica.

37 Segalés, J. (2000). La cláusula de conciencia del profesional de la información como sujeto de una relación laboral, Valencia, Tirant lo Blanch, pp. 256-257. 
to, porque tal cosa no deriva necesariamente del art. 20.1.d) CE (no en vano, el art. 2 de la Ley emplea el término «relación jurídica» y no «contrato»). Existen otras fórmulas jurídicas mediante las que un profesional de la información se puede vincular a un medio de modo que su autonomía para escoger un tema a tratar o el enfoque subjetivo para hacerlo resulte condicionada por existir subordinación funcional, y en todas ellas la reducción de su libertad puede devenir en una restricción ilegítima de su independencia o una lesión de su libertad de pensamiento. Es el caso del trabajador autónomo que actúa por encargo expreso de un empresario y bajo sus órdenes, instrucciones y directrices de modo que cede a éste sus derechos de explotación y publicación de su obra. Con independencia de la permanencia del vínculo, se le debe considerar sujeto de una relación asimilable a una de tipo laboral aunque, estrictamente, sea un colaborador y no miembro de la plantilla de la empresa; por tanto, en principio y a falta de concretar sus funciones, podría ser pleno titular de las facultades que recoge la LO 2/1997 ${ }^{38}$. En la misma situación estarían los profesionales vinculados a las empresas de comunicación mediante fórmulas civiles o mercantiles que conduzcan al mismo resultado aunque no conlleven el grado de dependencia que implica un contrato de trabajo y aquellos que, aunque actúen por libre, dependan económicamente de una sola o unas pocas empresas. Los profesionales completamente autónomos que ofertan su trabajo libremente en el mercado (periodistas freelance) sí quedarían claramente fuera del ámbito de aplicación de la LO 2/1997, por lo que deberán fundamentar sus posibles pretensiones directamente en el reconocimiento constitucional del derecho ${ }^{39}$.

Esta concepción de la laboralidad resulta particularmente garantista para aquellos profesionales de la información autónomos pero económicamente dependientes de un único medio. Además, es la aproximación más coherente con la caracterización de la titularidad de la cláusula de conciencia que ha realizado el Tribunal Constitucional, quien ha relativizado la importancia de las características del vínculo contractual que une al profesional de la información con la empresa de comunicación (cuya existencia asume como premisa necesaria) para focalizar la atención en el desempeño efectivo de determinadas funciones dentro de ésta ${ }^{40}$.

Según el Alto Tribunal, la cláusula de conciencia puede ser invocada por aquellos sujetos que se ocupen de tareas «en las que la libertad informativa puede

38 Blasco Jover, C. (2009). Cit. p. 178-180. También Escobar Roca, G. (2002). Cit. pp. 145 y s.

39 Rojas Rivero. M. P. (2008). Cláusula de Conciencia y Extinción del Contrato, Cizur Menor, Thompson-Aranzadi, p. 52-53, aunque es evidente que esto plantea un problema a la hora de determinar el contenido del derecho en los supuestos extralegales, ya que no hay norma que lo precise y una aplicación analógica de la Ley dejaría en entredicho su utilidad.

40 STC 199/1999, de 8 de noviembre, FJ $4 .^{\circ}$ y $5 .^{\circ}$ 
verse involucrada» por contribuir «a la descripción del becho, a destacar ciertos aspectos de él, a lograr un enfoque ideológico determinado o a dotarle de una mayor o menor relevancia informativa», con independencia de su titulación académica, formación, colegiación, aptitudes o la denominación de su categoría profesional. La titularidad del derecho no se limita necesariamente a los periodistas redactores de noti$\operatorname{cias}^{41}$, sino que alcanza a todas aquellas personas cuya actividad profesional consista en el desarrollo de tareas informativas ${ }^{42}$, ya que son quienes gozan de capacidad para incidir, de manera decisiva, en la construcción o el resultado final de la noticia o del mensaje informativo a través de la conformación de sus elementos objetivos y subjetivos. Dicho de otro modo, abarcaría a todos los profesionales calificables como "portadores de tendencia», dejando fuera a quienes realicen tareas estrictamente técnicas que, por no comportar ningún tipo de aportación subjetiva, no son susceptibles de alterar la información de modo suficiente para condicionar la percepción que un futuro receptor pueda tener de la misma.

Las divergencias más notables en la doctrina se manifiestan respecto de la posible consideración como sujetos de la cláusula de conciencia de aquellos profesionales, permanentes o colaboradores, cuya labor se limita a la expresión de opiniones a través de un medio de comunicación (normalmente en sintonía con la línea de éste ${ }^{43}$. Si se entiende que la referencia del Tribunal Constitucional al ejercicio de la «libertad de información» ${ }^{44}$, como criterio determinante de la titularidad, lo es a la libertad para transmitir datos objetivos y veraces, quienes simplemente ejerzan labores de opinión no podrían acogerse a la cláusula de conciencia. Sin embargo, en línea con el párrafo anterior, parece más correcto pensar que tal mención se refiere realmente a la libertad de expresión como derecho que integra el conjunto de las libertades comunicativas, incluyendo la libertad de opinión. Además, es la visión que parece seguir la Exposición de Motivos de la LO 2/1997.

Lo cierto es que los profesionales de opinión se encuentran en una situación peculiar porque, si bien su labor no es estrictamente la de informar, el desempeño de sus tareas es especialmente sensible ante cambios en la línea editorial del medio o ante órdenes directas de sus superiores cuando suponen modificar la orientación de sus mensajes. Incluso la permanencia en el puesto de trabajo quedaría comprometida si se trata de un sujeto al que se identifica personalmente con un sesgo ideológico concreto. A esto hay que sumar que, mediante el ejercicio de su libertad de opinión, estos colaboradores están transmitiendo al

41 Rojas Rivero. M. P. (2008). Supra, p. 47.

42 SuÁrez Espino, M. L. (2009). Cit. p. 48.

43 A favor de su inclusión, por ejemplo, Llamazares Calzadilla, M. C. (1999). Cit. pp. 123-124; en contra Blasco Jover, C. (2009). Cit. p. 187.

${ }^{4}$ SSTC 199/1999, de 8 de noviembre, FJ 2. ${ }^{\circ}$, y 225/2002, de 9 de diciembre, FJ 4. ${ }^{\circ}$ 
receptor de los mensajes del medio una valoración subjetiva que condicionará su visión sobre todas o parte de las noticias que le lleguen. Aunque no ejerzan la libertad de información en sentido estricto, sí inciden en la construcción y los efectos del mensaje informativo, sólo que de manera indirecta aportando un enfoque ideológico determinado respecto de una noticia o tema. Así concebidos, entrarían dentro de los sujetos legitimados, según el Tribunal Constitucional, para invocar la cláusula de conciencia en los términos legales siempre que cumplan con el requisito de dependencia en su vínculo con el medio.

En conclusión, los profesionales que gestionan de alguna manera información se sitúan, por la propia naturaleza de su trabajo, en una posición delicada que debe ser reforzada en aquellas situaciones en que las divergencias, básicamente ideológicas, con el empleador puedan acabar repercutiendo negativamente en su posición laboral o jurídica. Por ello, un profesional de la información estará legitimado para invocar la cláusula de conciencia mientras ejercite efectivamente y de modo adecuado su libertad para construir, modular o transmitir un determinado mensaje a través del desempeño de sus funciones, de forma estable, en el ámbito de la comunicación institucionalizada; es decir, dentro de una empresa cuyo fin sea dar a conocer el resultado de su trabajo, respaldándolo o incluso asumiéndolo como propio.

\section{CONTENIDO Y ALTERNATIVAS A LA CLÁUSULA DE CONCIENCIA DE BASE IDEOLÓGICA DEL ART. 2 DE LA LO 2/1997}

El art. 2.1.a) de la Ley permite al profesional de la información invocar la cláusula de conciencia ante un «cambio sustancial de orientación informativa o línea ideológica» del medio de comunicación. Este primer supuesto se caracteriza como una respuesta a una modificación en la política editorial o el ideario de la empresa, susceptible de alterar el tratamiento o el enfoque de la información a partir de ese momento, que genera un conflicto subjetivo de valores entre el empleado y el empleador en relación al objeto de la prestación. Aunque se haya tratado de reorientar este supuesto hacia motivaciones basadas en el respeto a las condiciones de veracidad y objetividad de la información ${ }^{45}$, lo cierto es que resulta complicado inferir tal cosa de la dicción legal, que se plantea como una forma de responder a la ruptura de la convergencia ideológica ideal que debería existir entre empleado y empleador.

45 En esta línea, Molina Navarrete, C. (1999). Cit. p. 102, obviando, quizá, que la redacción definitiva de la Ley incorporó precisamente el factor ideológico en este supuesto frente a la caracterización basada en la integridad deontológica que realizaba la Proposición de Ley. 
El precepto no alude a las razones que puedan motivar el cambio por lo que se asume, implícitamente, que tal posibilidad constituye un ejercicio de la libertad de empresa de los titulares que en ningún caso estará condicionada por la orientación personal mostrada hasta ese momento por los empleados ${ }^{46}$. Tampoco se exige expresamente que el profesional acredite la existencia de un daño sobre sus convicciones o su dignidad personal a consecuencia de la medida, presumiéndose éste por el mero hecho de invocar la cláusula de conciencia sin posibilidad de prueba en contra ${ }^{47}$. Finalmente, la conexión de esta modalidad de cláusula de conciencia con la libertad de pensamiento individual se aprecia claramente en el hecho de que corresponde al profesional, conforme a parámetros subjetivos, apreciar la existencia de la contradicción entre la nueva línea de la empresa y su fuero interno y valorar si la intensidad de la misma es suficiente como para impedirle continuar con el desarrollo de su labor en ella tal y como venía haciendo.

No obstante, el recurso efectivo a la cláusula de conciencia no queda plena y únicamente en manos de la voluntad del profesional, ni siquiera mediando una justificación razonable y por mucho que se sienta violentado ante las nuevas circunstancias con las que se encuentra, porque la norma incorpora un cierto componente objetivo. En primer lugar, el desajuste entre la orientación del medio y la del trabajador debe derivar de una mutación en la empresa posterior al inicio del vínculo con el sujeto y no ser consecuencia de un cambio en las convicciones o la concepción de la profesión de éste. Este supuesto se plantea como una reacción personal ante circunstancias nuevas que alteran los presupuestos materiales de desarrollo del trabajo periodístico y modifican el marco subjetivo de la prestación, haciendo que el profesional se pueda sentir incómodo como responsable de presentarlo ante la sociedad ${ }^{48}$, con independencia del efecto que el cambio pueda suponer sobre la opinión pública.

Además, la Ley impone que el cambio en la política editorial o el sustrato ideológico que modula el tratamiento de la información por parte del medio debe ser sustancial, cosa que matiza el elemento subjetivo en su apreciación. Esto significa, a juicio de la doctrina, que debe tratarse de una modificación objetiva y reiterada, es decir, apreciable como evidente e indubitada por la mayoría de la redacción del medio y por la opinión pública y persistente en el tiempo ${ }^{49}$. Además, parece lógico exigir que se trate de un cambio que afecte a los elementos

46 Rojas Rivero. M. P. (2008). Cit. p. 89.

47 Molina Navarrete, C. (1999). Supra, p. 125.

48 Segalés, J. (2000). Cit. p. 389.

49 Carrillo, M. (1997). Cit. pp. 189-190. Para SuÁrez Espino, M. L. (2009). Cit. p. 44, debe tratarse de un cambio brusco, no paulatino, en la línea del medio, por lo que cabría deducirse que también debe ser inesperado. 
principales y básicos del ideario o la orientación informativa, y no sólo a sus aspectos secundarios o accesorios ${ }^{50}$. Más dudas plantea la exigencia de que se trate de una modificación deliberada, pretendida expresamente por la dirección del medio, porque la Ley plantea el supuesto en términos de resultado, con independencia de que éste sea consecuencia de una decisión expresa de los responsables del medio o derive indirectamente de otras medidas.

El recurso a la cláusula de conciencia también cabe, conforme a la letra b) del art. 2.1 de la LO 2/1997, cuando la empresa traslade al sujeto «a otro medio del mismo grupo que por su género o línea suponga una ruptura patente» con su orientación profesional. Este segundo supuesto se define sin atender a las motivaciones o razones que tenga el empresario para llevar a cabo tal actuación, por lo que podrá invocarse ante una medida abusiva o arbitraria de la dirección del medio que constituya una sanción encubierta o una represalia para el profesional, pero también como forma excepcional de respuesta frente a una decisión legítima del mismo que cumpla con los requisitos que el ET establece en sus arts. 39 y 40 para la movilidad laboral. La doctrina no ha considerado importante que el cambio de medio implique movilidad geográfica para el sujeto o la asignación de funciones diferentes a las que venía desempeñando ${ }^{51}$, aunque sí que el origen y el destino formen parte de la misma empresa o del mismo grupo empresarial, que se identifica por el sometimiento al control de una única dirección ${ }^{52}$. El elemento esencial del supuesto es que se provoque una ruptura, una alteración grave, en la orientación profesional del periodista que sea visible y públicamente notoria (patente); en suma, que responda a los mismos criterios objetivos que se exigían para la primera modalidad de ejercicio del derecho.

Esto lleva a la necesidad de precisar qué se entiende por orientación profesional, considerando que, en abstracto, todo traslado a un medio de distinto género al de origen ya implica por definición una alteración en la misma ${ }^{53}$. Aunque la Ley no define el concepto, parece claro que no es el conjunto de tareas de un puesto concreto. Tampoco se identifica con la integridad deontológica, expresión empleada en la Proposición de Ley que no se plasmó en el articulado definitivo. Se ha sugerido que la orientación profesional del periodista hace referencia a su perfil profesional y a sus intereses y expectativas de futuro de mantenerse en un medio con un género o línea determinados ${ }^{54}$, lo que convertiría esta modalidad de cláusula de conciencia en un mecanismo para proteger la dignidad

\footnotetext{
50 Blasco Jover, C. (2009). Cit. p. 238.

51 Rojas Rivero. M. P. (2008). Cit. p. 79

52 Segalés, J. (2000). Cit. p. 458.

53 Ibidem, p. 82.

54 Blasco Jover, C. (2009). Supra, p. 243.
} 
profesional del periodista pero, al mismo tiempo, en una mera especificación del art. 50.1.a) ET sin entidad propia ${ }^{55}$. Este precepto ya permite a cualquier trabajador reaccionar ante modificaciones sustanciales en sus condiciones laborales que menoscaben su dignidad, obteniendo por ello la indemnización correspondiente al despido improcedente, por lo que no parece muy lógico interpretar la mención del art. 2.1.b) de la LO 2/1997 de manera que se solape con él ${ }^{56}$. Ambas previsiones sólo podrían diferenciarse en el caso de que la asignación al profesional de nuevas funciones constituyese una modificación sustancial de las condiciones de trabajo conforme al art. 41 ET. Tal medida está expresamente excluida del ámbito del art. 50.1.a) ET pero sí es potencialmente integrable dentro del alcance de la cláusula de conciencia conforme a la interpretación de la orientación profesional mantenida más arriba. Aunque, para ello, debe guardar una finalidad específica relacionada con el ejercicio del derecho a la información que justifique la invocación de este derecho.

Pero el principal problema de equiparar la orientación profesional con el derecho a una carrera profesional digna es que éste es un bien jurídico desconectado de las finalidades que se atribuyen a la cláusula de conciencia. Por ello, parece más coherente con el conjunto de la norma entender que la letra b) del art. 2.1 de la LO 2/1997 sirve para hacer frente a abusos o arbitrariedades por parte de la dirección del medio que afecten a la independencia ideológica del informador en el caso específico de que se materialicen a través de un cambio de destino dentro de una empresa de comunicación o grupo de ellas ${ }^{57}$. Al variar las condiciones, los ámbitos materiales de los que se ocupa o el enfoque del medio concreto en el que presta sus servicios, el profesional no podrá seguir proyectando su legítima orientación personal sobre los contenidos informativos (con objeto de generar información veraz, eso sí) o su labor de opinión tal y como venía haciéndolo, por lo que su libertad de expresión, y su libertad de pensamiento en última instancia, se resentirán. No obstante, resulta evidente que las limitaciones de la previsión normativa, en cuanto a las características de la movilidad exigida ${ }^{58}$, ponen en entredicho su eficacia, y más aún si se quiere valorar

55 Molina Navarrete, C. (1999). Cit. pp. 135-136 y 139.

56 Aunque este solapamiento no se daría totalmente en caso de que, al invocar la cláusula de conciencia, el profesional de la comunicación pudiera beneficiarse de una indemnización pactada mayor a la correspondiente por despido improcedente, lo cual no dejaría de ser una razón puramente práctica desconectada de la conceptualización teórica del derecho.

57 Rojas Rivero. M. P. (2008). Cit. pp. 79-80.

58 Para paliar esta insuficiencia, Blasco Jover, C. (2009). Cit. pp. 244 y s. propone que la cláusula de conciencia también debería poder invocarse frente a traslados entre secciones del mismo medio siempre que se afecte a la orientación profesional del sujeto que los sufre. 
su alcance como garantía ante posibles represalias derivadas de la invocación de la propia cláusula de conciencia en otros supuestos.

Así entendidos, los requisitos definitorios de las dos modalidades del art. 2.1 de la LO 2/1997 se plantean en términos que resultan perfectamente alineados con uno de los objetivos particulares que se atribuyen a la cláusula de conciencia (pero no con los demás): la protección de la independencia del profesional de la información en su faceta ideológica frente a actos de la empresa que la alteren de manera real y grave. Puesto que se trata de un valor activo que tiene sentido en la medida en que pueda plasmarse realmente en el ejercicio de las libertades comunicativas, y dado que la actuación empresarial pone en evidencia que el sujeto ha perdido la posición de confianza de la que debe disfrutar para realizar su trabajo ${ }^{59}$, la consecuencia coherente de invocar el derecho debería ser la construcción alrededor del profesional de una «zona de comodidad» en el desempeño de la tarea periodística en la que se vea a salvo de todo intento de la dirección de hacerle actuar de manera contraria a sus convicciones mientras se mantenga dentro de los límites impuestos por las reglas deontológicas. Sin embargo, las previsiones normativas al respecto se mueven en otro sentido.

La única facultad que otorga la cláusula de conciencia según el art. 2 de la Ley es la de solicitar «la rescisión de su relación jurídica con la empresa de comunicación en que trabajen», obteniendo por ello «una indemnización, que no será inferior a la pactada contractualmente o, en su defecto, a la establecida por la Ley para el despido improcedente». Esto la convierte en un simple mecanismo compensatorio para el profesional de la información, una facultad reactiva ante decisiones empresariales perjudiciales que en absoluto sirve para proteger el ejercicio activo o pasivo de la libertad de comunicación y que, entendida así, no encuentra cabida en los objetivos autoproclamados por la Ley. El propio Tribunal Constitucional parece insistir en esto cuando caracteriza la indemnización como un componente central de la cláusula de conciencia, ya que reconoce a su titular la posibilidad de obtenerla después de haber tenido que recurrir a la rescisión de su contrato ${ }^{60}$, como una compensación por el daño que le supuso la situación en la que estaba. El problema es que si se asume que la única solución para que los profesionales de la información no sufran perjuicios por razón de su legítima discrepancia con la nueva tendencia editorial de la empresa o sus decisiones organizativas es abandonarla, se está admitiendo, implícitamente, que están en una irremediable situación de indefensión en el ejercicio de su trabajo, sometidos a los dictados de la empresa, porque la Legislación no ofrece forma efectiva de no estarlo.

\footnotetext{
59 Segalés, J. (2000). Cit. p. 406.

${ }^{60}$ STC 225/2002, de 9 de diciembre, FJ 5. ${ }^{\circ}$
} 
El hecho de que se garantice que aquellos trabajadores que se ven impelidos a abandonar su puesto de trabajo para salvaguardar sus convicciones reciban una indemnización privilegiada no es en absoluto criticable. Como tampoco lo es reconocer que la eficacia de la cláusula de conciencia no está sujeta a plazo, porque se presenta como un derecho fundamental. Lo que sí es digno de una valoración negativa es que la única solución prevista para el conflicto ideológico sobrevenido entre la empresa y el profesional sea la rescisión contractual, ya que eso muestra una concepción muy limitada del derecho y contradictoria con las propias proclamas del Tribunal Constitucional sobre su finalidad social, por no hablar de lo insatisfactoria que puede ser para el sujeto y lo poco acorde que resulta con las circunstancias actuales.

No es del todo cierto que, al rescindir su contrato, el profesional de la información recupere su libertad activa de expresión al no tener que respetar más las pautas impuestas por el medio. Lo que sucede es que en ese momento recobra la plena capacidad de ejercer una facultad subjetiva que había visto modulada, pero nunca había perdido porque es irrenunciable. El problema es que la recupera como ciudadano, no como el titular particularmente cualificado que era hasta ese momento por razón del alcance que podía darle. Y dado que el fin de la cláusula de conciencia es proteger la independencia en el desempeño de la función periodística, y no la independencia personal en abstracto o alejada de tal la posibilidad, la falta de idoneidad de la previsión del art. 2 de la Ley resulta patente.

Por ello, cabe valorar la viabilidad o la necesidad de otras opciones que puedan solucionar la situación de aquellos profesionales que no comparten la tendencia de la dirección sin condenarles a perder su trabajo, sobre todo teniendo en cuenta las dificultades que previsiblemente encontrarán para recalar en otra empresa de comunicación a la vista de la concentración y polarización del sector y lo complicado del mercado laboral específico en el que se mueven. Y dado que su finalidad sería permitir al profesional de la información continuar en la empresa, su aplicación deberá contar necesariamente con el beneplácito de éste. Corresponde al implicado ponderar, en función de sus circunstancias personales o profesionales, si está dispuesto a mantenerse en un medio con el que tiene abierto un conflicto y en qué condiciones, toda vez que eso le va a suponer inevitablemente algún tipo de sacrificio.

Aunque no de manera pacífica, se ha planteado como posible alternativa la acomodación del periodista en otra sección del medio menos proclive a ocasionarle problemas de conciencia siempre que sea posible en términos económicos, organizativos y técnicos y no afecte de modo desproporcionado al funcionamiento de la empresa de comunicación, aunque sólo para el supuesto de mutación ideoló- 
gica $^{61}$. A partir de la doctrina constitucional que entiende que un empleador está obligado a adoptar el esquema organizativo y tomar las decisiones de gestión que generen el menor sacrificio posible de los derechos fundamentales del trabajador ${ }^{62}$, surgiría para éste un derecho, constitucional, a que su prestación sea adaptada a sus creencias y valores morales, lo que en el caso de las empresas de comunicación tendría como solución natural el cambio a un puesto donde el sujeto no vea afectadas sus convicciones y éstas, tal como quiere la empresa, no repercutan en los contenidos como lo venían haciendo. El potencial de esta posibilidad como solución de compromiso para el conflicto que desemboca en la invocación de la cláusula de conciencia es claro y permite mantener cierto grado de independencia en el ejercicio de la función informativa para el profesional al tiempo que el medio no ve alterada su línea editorial, por lo que su inclusión en la Ley o en los distintos Estatuto de Redacción como forma de ejercicio de aquella es perfectamente defendible. Pero no como una obligación inmediata del empresario, sino como resultado, necesariamente, de un pacto entre las partes. En caso contrario se corre el riesgo de que la posible solución al conflicto acabe resultando más lesiva para los intereses del profesional que el mal que se pretende evitar, ya que éste trae causa de una situación que le resulta, por definición, insostenible.

Lo que, por el contrario, no encuentra buena recepción en la doctrina es la posibilidad de que, a través de la cláusula de conciencia, el profesional pudiera mantenerse en su puesto tras la mutación en la tendencia de la empresa o ante la pretensión de cambiarle de medio, continuando con sus funciones conforme a su propio criterio ideológico y no al establecido por la dirección. Esto supondría dotar de una expansión máxima a la libertad de pensamiento de aquel que, como contrapartida, obligaría a la empresa a tolerar la libre expresión del profesional mientras siga en su puesto, lo que implicaría una congelación del cambio ideológico que podría derivar en un perjuicio posiblemente irreparable ${ }^{63}$. De ahí que sea necesario ponderar esta opción de modo que el interés definitorio de las empresas de comunicación, que es el establecimiento de su línea editorial, no resulte afectado de manera desproporcionada.

Pero además de generar un conflicto con la libertad de empresa, el verdadero riesgo de esta solución es que se genere una «apariencia engañosa para las personas que reciben la información» a causa de la permanencia en sus funciones del profesional que ha invocado la cláusula de conciencia ${ }^{64}$. Atendiendo a esto último, la

${ }^{61}$ Es la tesis de Molina Navarrete, C. (1999). Cit. p. 179-182, de donde se toma cuanto sigue al respecto.

${ }^{62}$ SSTC 99/1994, de 17 de mayo, FJ 4. ${ }^{\circ}$, y 106/1996, de 12 de junio, FJ 5. ${ }^{\circ}$

63 Segalés, J. (2000). Cit. p. 419.

${ }^{64}$ STC 225/2002, de 9 de diciembre, FJ $4 .^{\circ}$ in fine. 
viabilidad de esta solución dependería de la adopción de cautelas que garantizaran la previsibilidad en la orientación de los contenidos del medio exigida por el principio de veracidad de la información, siempre que no sea, por definición, un medio plural. Tal cosa se podría lograr, por ejemplo, permitiendo a los profesionales permanecer en su puesto y realizar reportajes disidentes con la línea editorial sólo si se identifican fehacientemente de modo que el público sepa que se separan de ella. Quizá también limitando la presencia global de esos trabajos en los contenidos del medio, con la finalidad de que los profesionales no alineados con él no puedan, en la práctica, alterar su tendencia. En todo caso, no resulta sencillo, y está claro que la libertad de actuación de los periodistas que no comparten la línea de la empresa en la que trabajan no podría ser nunca completamente plena.

No obstante, una concepción así de la cláusula de conciencia podría, incluso, tener un efecto positivo inesperado sobre la formación de la opinión pública. El pluralismo social se vería beneficiado si en los medios privados, cerrados en su línea ideológica, pudieran exponerse, aunque fuera de manera reducida, opiniones variadas y divergentes. Así llegarían a una audiencia en parte polarizada que, de otro modo, jamás se abriría a conocer opciones discrepantes, lo cual repercutiría en la calidad del debate democrático y en la formación de los ciudadanos. Y esto es algo que, se supone, debe promoverse por encima de los intereses empresariales.

\section{LA CLÁUSULA DE CONCIENCIA RESISTENTE}

La tercera facultad contemplada en la LO 2/1997 como parte de la cláusula de conciencia se define en términos bastante diferentes a los supuestos anteriores. Su art. 3 establece que «los profesionales de la información podrán negarse motivadamente a participar en la elaboración de informaciones contrarias a los principios éticos de la comunicación, sin que ello pueda suponer sanción o perjuicio», ampliando el ámbito del derecho más allá del supuesto y la consecuencia tradicionales ${ }^{65}$. No obstante, los posteriores pronunciamientos del Tribunal Constitucional han incluido la protección de la integridad deontológica dentro de las finalidades a las que se orienta el reconocimiento de la cláusula de conciencia como un elemento esencial para garantizar las libertades comunicativas por lo que, actualmente, no existe razón para sostener que el contenido del precepto sea un añadido extraño a la regulación, sobre todo teniendo en cuenta la necesaria evolución que deben experimentar los derechos en su contenido.

${ }^{65}$ Por esta razón, la doctrina, como Carrillo, M. (1997). Cit. p. 191-192, consideró inicialmente que, a pesar de su inclusión en la Ley, el contenido de este precepto no formaba parte de su objeto. 
Se reconoce un derecho de resistencia del profesional de la información ante un ejercicio del poder de dirección empresarial contrario a la deontología profesional, pero no se requiere necesariamente la existencia de una modificación de la forma de proceder o de la línea ideológica del medio. Su invocación puede ser consecuencia de una instrucción nueva que ordena actuar de modo contrario a unos principios éticos cuyo respeto se había exigido hasta entonces, rompiendo con la situación precedente en la que el profesional prestaba sus servicios. Pero también cabe el planteamiento sobrevenido, derivado de un cambio en la valoración que merece para el sujeto el hecho de venir realizando, como parte de sus funciones y a petición de sus superiores, trabajos que se desvían de las reglas de la ética periodística. En ambos casos se daría el presupuesto exigido por la norma: un incumplimiento por parte del empresario de las obligaciones que impone el legítimo ejercicio del derecho a la información que el trabajador entiende lesivo de los principios éticos de la comunicación ${ }^{66}$. Aunque esta consideración tenga carácter subjetivo, resulta necesario precisar, en términos objetivables, cuáles son esos principios que convierten en desviada la conducta del empleador que aboga por su inobservancia. La exigencia de motivación que impone el precepto implica que se debe identificar la regla o reglas deontológicas de cuyo incumplimiento se pretende huir.

Se podrían considerar como tales las pautas contenidas en los diversos instrumentos supranacionales que se refieren a la profesión periodística, como los Principios Internacionales de Ética Profesional del Periodismo o el Código Deontológico Europeo de la Profesión Periodística ${ }^{67}$, aunque su aplicabilidad está condicionada por su ineficacia como guías interpretativas de las normas nacionales ${ }^{68}$. De inexcusable observancia sí serian aquellas recogidas expresamente en normas nacionales o derivadas de su contenido ${ }^{69}$. Así, constituyen principios éticos de la profesión periodística el deber de respetar el principio de veracidad de la información y el resto de los límites a la libertad informativa establecidos por la propia Constitución y la jurisprudencia del Tribunal Constitucional, el respeto a los derechos reconocidos a los espectadores en la Ley

66 Rojas Rivero. M. P. (2008). Cit. p. 117.

${ }^{67}$ El primero es el Código Internacional de Ética Periodística de la UNESCO de 21 de noviembre de 1983. El Código Europeo se aprobó mediante la Resolución 1003 (1993), de 1 de julio de 1993, de la Asamblea Parlamentaria del Consejo de Europa, complementada con la Recomendación 1215 (1993).

68 Únicamente las sentencias del TEDH pueden emplearse como referente interpretativo de los derechos reconocidos la Constitución a través del art. 10.2 CE, no sirviendo para ello los pronunciamientos emanados de la Asamblea Parlamentaria del Consejo de Europa (STC 114/1984, de 29 de noviembre, FJ 3. ${ }^{\circ}$ ), afirmación que sería extensible por analogía a los trabajos emanados de otros órganos consultivos internacionales.

${ }^{69}$ Blasco Jover, C. (2009). Cit. pp. 300-303. 
7/2010, de 31 de marzo, General de la Comunicación Audiovisual ${ }^{70}$, y las obligaciones para los periodistas que puedan derivarse de las distintas leyes nacionales y autonómicas que regulan los medios de titularidad pública. También podrían entrar en esta enumeración los principios éticos recogidos en el vigente Estatuto de la Profesión Periodística de 1967, si bien estos deben entenderse esencialmente superados por el actual marco constitucional.

Por último, y para añadir mayor confusión a la lista, habría que sumar aquellos deberes que específicamente se impongan a los profesionales de un medio concreto a través de los convenios colectivos o Estatutos de Redacción, así como los recogidos en las normas de autorregulación dictados por los prestadores de servicios audiovisuales al amparo del art. 12 de la Ley 7/2010, especialmente el Código de Autorregulación de Contenidos Televisivos e Infancia. Incluso se podrían considerar las pautas de actuación profesional consuetudinarias, no positivizadas, que sean aceptadas en un medio o subsector concreto, pero aunque la Ley no las excluye, su invocación presenta un evidente problema de prueba. Así las cosas, y aunque existan coincidencias entre los diferentes textos, resulta muy complicado precisar un catálogo cerrado de principios éticos de la comunicación con lo que, en la práctica, las posibilidades del profesional para fundamentar su pretensión son bastante amplias. Lo único que parece fuera de duda es que la indeterminación del concepto no puede servir de excusa para introducir las simples discrepancias ideológicas como presupuesto de esta modalidad del derecho.

Toda orden del empresario que exhorte al trabajador a incumplir algún principio identificable como parte de la ética periodística constituirá un ejercicio irregular de su poder de dirección frente al que la Ley reconoce al profesional una garantía de indemnidad. Se le legitima para incumplir el mandato empresarial por existir justa causa, al tiempo que se proclama su inmunidad frente a cualquier decisión perjudicial que adopte el empresario como respuesta a su desobediencia, ya sea una sanción, una represalia expresa o encubierta o una medida que pretenda paliar o mitigar los efectos del incumplimiento, incluyendo el despido disciplinario. Pero, en el fondo, esta modalidad de la cláusula de conciencia no es una facultad excepcional ni un privilegio que se atribuya a los profesionales de la información, sino el reconocimiento explícito de una evidencia: en el sector de la comunicación, por la particular repercusión de su actividad en la formación de la

${ }^{70}$ En cuyos arts. 4 a 9 se recogen, mediante una formulación compleja y casuística, múltiples derechos específicos del público agrupados en diversas categorías: los destinados a garantizar la recepción de una comunicación audiovisual plural, los dirigidos a asegurar la diversidad cultural y lingüística, los relativos a la transparencia de la comunicación audiovisual, aquellos específicamente referidos a los menores de edad o a las personas con discapacidad, y los derechos de participación en el control de los contenidos audiovisuales. 
opinión pública, la empresa no puede imponer a sus trabajadores la realización de actividades contrarias a la deontología profesional (igual que sucede en otros ámbitos, por otra parte). Tal y como se han caracterizado, los principios éticos de la comunicación constituyen, en su mayoría, deberes vinculantes para quienes participen activamente en la misma. Algunos porque, antes que pautas informadoras de la actividad periodística, son obligaciones directamente impuestas por una norma jurídica; y otros porque se recogen en los códigos deontológicos vigentes, textos cuyas disposiciones son de obligado cumplimiento para los profesionales incluidos en su ámbito de aplicación ${ }^{71}$. En los términos del art. 3 de la LO 2/1997, la cláusula de conciencia resistente sólo asegura que los profesionales de la información podrán proceder de la manera debida en Derecho, incumpliendo el mandato antijurídico, a salvo de coacciones, razón por la que tampoco se puede calificar como un supuesto de objeción de conciencia.

Por esta razón, la cláusula de conciencia resistente se debe entender como un mecanismo dirigido a proteger la integridad del periodista en el ejercicio de sus funciones que, como contrapartida, resulta completamente ineficaz para asegurar el derecho a recibir información veraz y la adecuada formación de la opinión pública, por mucho que el titular pudiera tener esa pretensión al invocarla. El hecho de que un profesional concreto se oponga a elaborar un reportaje que contraviene algún principio deontológico, o se niegue a firmar una información manipulada ${ }^{72}$, no va a impedir que estos vean la luz, lleguen a sus destinatarios y alteren la percepción de la opinión pública respecto del hecho noticioso. La decisión de no infringir las normas de la ética profesional es estrictamente personal y fruto de una valoración individual de los intereses implicados que para nada condiciona la que puedan adoptar la dirección o el resto de trabajadores del medio al respecto. En esta línea, la Ley tampoco prevé medidas para permitir que la decisión del sujeto tenga una trascendencia real sobre el proceso informativo. No se establece obligación alguna de denunciar la conducta impropia del empresario, ni se faculta a ningún empleado del medio para adoptar o promover medidas destinadas a evitar la publicación del reportaje desviado, como tampoco se prevén

71 Conforme a la STC 219/1989, de 21 de diciembre, FJ 5. ${ }^{\circ}$, "las normas de deontología profesional aprobadas por los Colegios profesionales o sus respectivos Consejos Superiores u órganos equivalentes no constituyen simples tratados de deberes morales sin consecuencias en el orden disciplinario. Muy al contrario, tales normas determinan obligaciones de necesario cumplimiento por los colegiados y responden a las potestades públicas que la Ley delega en favor de los Colegios para «ordenar... la actividad profesional de los colegiados, velando por la ética y dignidad profesional y por el respeto debido a los derechos de los particulares» (art. 5 i) de la Ley de Colegios Profesionalest».

72 Siempre que se considere que esta posibilidad está incluida en la cláusula de conciencia resistente positivizada, cosa no del todo clara. Vid. Molina Navarrete, C. (1999). Cit. p. 182. 
fórmulas que permitan al profesional que manifiesta su disconformidad con el tratamiento de la información dar a conocer su versión alternativa una vez publicada ésta. Las consecuencias del recurso a esta modalidad del derecho nunca van a trascender de la relación jurídica personal del periodista que la invoque con la empresa, por mucho que se le quiera dotar de un fundamento objetivo.

$Y$ de hecho es discutible que deban hacerlo, porque la garantía de la dignidad profesional, desde el punto de vista deontológico, es una finalidad suficiente para justificar el reconocimiento de la cláusula de conciencia resistente en el Ordenamiento. Cada profesional puede y debe hacerse responsable de su trabajo, y procurar que su participación en el proceso informativo se realice observando las garantías exigidas, pero no hay razón para convertirlo en el guardián de la ética de todo cuanto hace o decide el medio en el que se integra, cosa para la que tampoco está capacitado. El problema es que, incluso concebida como una facultad de alcance individual y limitado, su eficacia práctica es menor de lo que sería deseable. Se reconoce en términos genéricos, sin contemplar ninguna garantía o medida concreta para el caso de que sus titulares fueran realmente sancionados o perjudicados por negarse a acatar la orden desviada, ni solventar qué sucedería en caso de invocación no adecuada o errónea ${ }^{73}$.

El resultado final es que, al igual que sucedía con la modalidad rescisoria, la cláusula de conciencia resistente se recoge normativamente en términos que desincentivan su utilización por parte de los profesionales de la información. La consideración del respeto a las reglas deontológicas como un factor capaz de modular el deber de obediencia del empleado no impide que la dirección del medio, al final, siga manteniendo el control sobre el proceso de generación de contenidos informativos. Con ello, ese «efecto silenciador del mercado» sobre la disidencia que, según el Tribunal Constitucional, ayuda a paliar la cláusula de conciencia $^{74}$, se mantiene, cosa inexplicable cuando, como en este caso, ésta es precisamente la actitud correcta que permitiría garantizar la veracidad y objetividad de la información frente a manipulaciones.

\section{CONCLUSIONES}

La cláusula de conciencia se inserta en el Ordenamiento como un instrumento jurídico formalmente muy complejo en cuanto a su objeto de protección. Teóricamente planteada como una garantía de la independencia ideológica y deontológica del profesional de la información, la jurisprudencia y la doctrina

73 Blasco Jover, C. (2009). Cit. p. 307.

${ }^{74}$ STC 199/1999, de 8 de noviembre, FJ 3. ${ }^{\circ}$ 
parecen supeditar estos valores de forma absoluta a la protección efectiva de la libre formación de la opinión pública como finalidad social de la actividad periodística. Da la impresión de que el profesional de la información sólo podrá obtener la tutela ante abusos o conductas desviadas del medio para el que trabaja cuando éstas puedan producir una alteración real y relevante de la percepción social de las informaciones emitidas, lo cual, de inicio, le resta eficacia como el derecho fundamental y la garantía individual que, se supone, se consagra en la Constitución.

Esto podría salvarse si se interpreta que la cláusula de conciencia protege el correcto desarrollo y los fines del proceso comunicativo no de manera directa, sino indirectamente como consecuencia de garantizar la libertad de expresión y la integridad profesional de sus titulares en el ejercicio activo de su trabajo mientras lo desarrollan al servicio de un medio. Ambas son la base de la libertad del profesional de la información para ejercer, siempre correctamente, la comunicación por las vías institucionalizadas ante la sociedad, por lo que deberían beneficiarse de prerrogativas especiales para garantizar su ejercicio, admitiendo modulaciones únicamente en dos casos: cuando la libertad de empresa y el derecho de ésta a mantener una tendencia puedan legítimamente restringirlas por existir un verdadero pluralismo de medios que haga innecesaria la promoción especial del pluralismo interno y cuando la proyección de esos aspectos subjetivos no resulte beneficiosa para la sociedad y la opinión pública.

Sin embargo, y aunque la titularidad del derecho se define a partir del ejercicio activo de la libertad de expresión en sentido amplio, el contenido positivizado en la LO 2/1997 o en las normas de autorregulación no sirve para proteger ni ésta ni la libre formación de la opinión pública, dando lugar a una configuración incoherente en la que aquel derecho queda completamente diluido. Las facultades que se reconocen al profesional no tienen un efecto real sobre el proceso comunicativo y su invocación resulta muy poco atractiva para sus titulares. El contenido clásico de la cláusula de conciencia no se ajusta bien a las circunstancias actuales, en las que el abandono del puesto de trabajo como única salida ante una discrepancia ideológica supone, realmente, ceder ante la coacción de la empresa. Siendo realistas, implica un perjuicio para el sujeto y la privación práctica de su libertad de expresión como profesional de la información. La solución de las discrepancias ideológicas en el seno de la empresa de comunicación exige la previsión normativa de otras salidas más proporcionadas. Sólo la modalidad resistente del art. 3 de la Ley se puede considerar un mecanismo eficaz para garantizar la independencia periodística en su dimensión deontológica con un alcance estrictamente personal, pero la incomprensible falta de previsión de ulteriores garantías para el sujeto lleva a su ineficacia práctica. 
Como consecuencia, la naturaleza de la cláusula de conciencia como verdadero derecho fundamental queda en entredicho en el Ordenamiento español, lo que hace incluso plantearse la conveniencia de su reconocimiento constitucional. Su redefinición tomando como punto de partida la dignidad del profesional resulta imprescindible si se la quiere convertir en una verdadera garantía de la libertad de expresión y del derecho a recibir información libre y veraz. Porque actualmente, en lugar de ser una vía para resaltar la importancia del profesional individual en un entorno dominado por los medios y los intereses empresariales, es un recurso testimonial que sólo sirve para mantener el statu quo en el sector.

\section{BIBLIOGRAFÍA}

Abejón Mendoza, P. (2013). «Estado del periodismo de opinión en España: polarización, género y emolumentos». Zer. Revista de Estudios de Comunicación, vol. 18, n. $^{\circ} 34$, pp. 93-109.

Abel Vilella, F. A. (2002). La concentración de los medios de comunicación social en los derechos español y comunitario, Madrid, Marcial Pons.

Aznar, H. (1998). «Cláusula de conciencia e información: de la ideología a la ética profesional». Revista de Estudios Políticos, n. ${ }^{\circ} 100$, pp. 291-310.

Azurmendi, A. (2011). Derecho de la comunicación, Barcelona, Bosch.

Blasco Jover, C. (2009). El derecho a la cláusula de conciencia de los profesionales de la información, Albacete, Bomarzo.

Calvo Gallego, F. J. (1998). «Algunas reflexiones sobre la nueva Ley de la cláusula de conciencia». Relaciones Laborales, n. ${ }^{\circ} 1$, pp. 11-45.

Carreras Serra, L. (1996). Régimen jurídico de la información: periodistas y medios de comunicación, Barcelona, Ariel.

Carrillo, M. (1997). «La Ley Orgánica de la cláusula de conciencia de los periodistas: una garantía atenuada del derecho a la información». Cuadernos de Derecho Público, n. ${ }^{\circ} 2$, pp. 177-193.

Escobar de la Serna, L. (1997). «La cláusula de conciencia como derecho fundamental en la Constitución de 1978», en Escobar de la Serna, L. (Dir.). La cláusula de conciencia, Madrid, Universitas.

- (2003). «El TC y la cláusula de conciencia». Doxa comunicación, n. ${ }^{\circ}$ 1, pp. 131-139.

Escobar Roca, G. (2002). Estatuto de los periodistas. Régimen normativo de la profesión y organización de las empresas de comunicación, Madrid, Tecnos.

FernándeZ-Miranda Campoamor, A. (1996). «Artículo 20: libertad de expresión y derecho de la información», en Alzaga Villaamil, O. (Dir.). Comentarios a la Constitución Española, T. II, Madrid, Edersa. 
Gavara de CARA, J. C. (2013). «La autorregulación como mecanismo de autocontrol de los medios de comunicación: intervención pública y regulación interna», en Gavara de Cara, J. C.; De Miguel Bárcena, J. (Eds.). La autorregulación de los medios de comunicación como sistema de control, Barcelona, Bosch.

Llamazares Calzadilla, M. C. (1999). Las libertades de expresión e información como garantía del pluralismo democrático, Madrid, Civitas.

Molina Navarrete, C. (1999). Empresas de comunicación y «cláusula de conciencia» de los periodistas, Granada, Comares.

Rojas Rivero, M. P. (2008). Cláusula de Conciencia y Extinción del Contrato, Cizur Menor, Thompson-Aranzadi.

SEgALÉs, J. (2000). La cláusula de conciencia del profesional de la información como sujeto de una relación laboral, Valencia, Tirant lo Blanch.

SuÁrez Espino, M. L. (2009). «Algunas reflexiones sobre el Estatuto Jurídico del Periodista en el Ordenamiento Jurídico español». Cuadernos de Derecho Público, n. ${ }^{\circ}$ 36, pp. 39-67.

VALDÉs DAL-RÉ, F. (2012). «Artículo 11. La libertad de expresión e información», en Monereo Atienza, C.; Monereo Pérez, J. L. (Dirs.). La Europa de los derechos. Estudio sistemático de la Carta de los Derechos Fundamentales de la Unión Europea, Granada, Comares.

Title:

PROBLEMS AND CONTRADICTIONS OF THE JOURNALISTS' CONSCIENCE CLAUSE REGULATION

\section{Summary:}

1. Introduction. 2. Modulations of the journalists' freedom of expression resulting from their job in a media. 3. Problems of the normative conscience clause basis and the diversity of protected legal assets. 4. Definition of the right's holders. 5. Content and alternatives to the ideological conscience clause of art. 2 LO 2/1997. 6. The «resistant» conscience clause. 7. Conclusions. 8. Bibliography.

\section{Resumen:}

El objeto de este trabajo es realizar un análisis crítico de la actual regulación de la cláusula de conciencia de los profesionales de la información, evidenciando sus carencias prácticas y contradicciones, 
cosa que hasta el momento la doctrina no ha terminado de plasmar con claridad. Al abordar esta cuestión, el Legislador y el Tribunal Constitucional han optado por crear un marco jurídico de fundamentación compleja, donde la integridad profesional, el derecho a recibir información y la salvaguarda del pluralismo como fundamento de la opinión pública libre se entremezclan para justificar un contenido que, sin embargo, resulta particularmente pobre en sus previsiones e ineficaz como garantía individual o social. La libertad de expresión, materialización de la independencia ideológica de los encargados de generar contenidos informativos y un elemento esencial del trabajo periodístico, parece quedar desplazada a un segundo plano cuando, precisamente, es a través de su garantía como mejor se puede asegurar la transmisión de una información que, sin dejar de ser objetiva, responda a la diversidad exigida por el principio democrático. Tras analizar si la cláusula de conciencia es un mecanismo efectivo para proteger la posición individual del periodista o los intereses sociales en relación con la actividad de los medios de comunicación, la conclusión es que se hace necesario redefinir esta institución, ya sea bien reconociéndola unas finalidades y un papel más modestos en el Ordenamiento, o dotándola de un contenido que sirva realmente para garantizar la libertad de comunicación de los periodistas para generar mensajes cuando trabajan para un medio y el derecho los ciudadanos a recibirlos adecuadamente.

\begin{abstract}
:
The objective of this paper is to critically analyse the actual regulation of the journalists' conscience clause, reflecting its practical shortcomings and contradictions, considering the doctrine has not reflected enough these particulars yet. When developing the journalists' conscience clause, the Spanish legislator and the Constitutional Court have created a complex legal framework, where the professional integrity, the right to information and the safeguarding of pluralism are appointed as the fundamental basis of the right. However, its content is particularly poor and ineffective as an individual or collective mechanism of protection. The freedom of expression, visible form of the ideological independence of the information contents' authors and an essential element of journalistic work, seem to be put to the background, but their guarantee is the best way to ensure the transmission of objective information that also meets the need for diversity required to satisfy the democratic principle. After analysing if the conscience clause is an effective protection mechanism of the journalist's individual position or the social interests related to
\end{abstract}


media informative activities, the conclusion is this institution should be redefined. It is necessary to give it a more modest role in the Legal System or to change its contents in order to really ensure the journalists' freedom of communication in a media and the citizens' right to correctly receive informative messages.

\section{Palabras clave:}

Libertad de expresión e información. Cláusula de conciencia. Pluralismo. Ética periodística. Independencia profesional.

\section{Keywords:}

Freedom of expression and information. Conscience clause. Pluralism. Journalism ethics. Professional independence. 
